\title{
The Use of Anti-Platelet and/or Anticoagulant Agents in the Prevention of Large Vessel Vasculitis-Associated Ischemic Complications: A Meta-Analysis
}

\author{
James Jeong, Lillian Barra* \\ Department of Medicine, University of Western Ontario, London, Canada \\ Email:
}

Received 13 April 2014; revised 13 May 2014; accepted 20 May 2014

Copyright (C) 2014 by authors and Scientific Research Publishing Inc.

This work is licensed under the Creative Commons Attribution International License (CC BY). http://creativecommons.org/licenses/by/4.0/

\section{(c) (i) Open Access}

\section{Abstract}

Objective: To determine the effectiveness of antiplatelet and/or anticoagulant therapy (AP/AC) at reducing ischemic events in patients with Large Vessel Vasculitis (LVV). Methods: We performed a random effects meta-analysis of studies examining antiplatelet and/or anticoagulant therapy (AP/AC) and ischemic events in Takayasu's Arteritis (TAK) or Giant Cell Arteritis (GCA). Severe ischemic events were defined as stroke, ischemic ocular manifestations and claudication symptoms. Any ischemic event included jaw claudication in addition to the above manifestations. Results: Seven studies met inclusion criteria: 1 TAK and 6 GCA. The majority of patients (>80\%) were treated with ASA and treatment was initiated prior to diagnosis of LVV. Risk of severe and any ischemic event in patients with LVV treated with AP/AC versus no treatment was not significantly different (OR 0.570, 95\% CI $0.243,1.340$ and OR $0.594,95 \%$ CI $0.248,1.421$, respectively). For studies with follow-up data (26-76 months), AP/AC was protective for severe ischemic events (OR $0.18,95 \%$ CI $0.04,0.83$ ). Findings were similar when excluding studies that did not account for potential confounders, such as cardiovascular risk factors. Conclusion: At follow-up, antiplatelet therapy significantly decreases ischemic events in patients with LVV. However, in most cases of GCA, the treatment was initiated prior to the diagnosis of vasculitis. The benefit of initiating anti-platelet therapy at the time of GCA diagnosis remains unclear.

\section{Keywords}

Giant Cell Arteritis, Takayasu's Arteritis, Large Vessel Vasculitis, Ischemic, Aspirin, Antiplatelet

\footnotetext{
${ }^{*}$ Corresponding author.
}

How to cite this paper: Jeong, J. and Barra, L. (2014) The Use of Anti-Platelet and/or Anticoagulant Agents in the Prevention of Large Vessel Vasculitis-Associated Ischemic Complications: A Meta-Analysis. Open Journal of Rheumatology and Autoimmune Diseases, 4, 114-123. http://dx.doi.org/10.4236/ojra.2014.42017 


\section{Introduction}

Large Vessel Vasculitis (LVV) refers to a rare condition of systemic inflammation with involvement of large and medium sized blood vessels. Two of the major types of LVV include Giant Cell Arteritis (GCA) and Takayasu's Arteritis (TAK). GCA affects patients over the age of 50 and affects women more often than men while TAK typically affects women under the age of 40 and has a predisposition for people of Asian descent [1] [2]. The incidence of both conditions is rare: 100 - 250 per million for GCA and 2.6 per million for TAK [1]-[3].

Although distinct entities, GCA and TAK share similarities in their pathogenesis [4], both conditions can result in ischemic complications which are the presenting symptoms at diagnosis. GCA frequently affects extra-cranial branches of the carotid artery resulting in jaw claudication, scalp tenderness, blindness, transient ischemic attacks (TIA), and strokes [5]-[10]. Limb claudication may also occur from involvement of the subclavian, axillary, and brachial branches [11]-[13]. TAK typically affects large arteries especially the aorta and may manifest as regional pain over the affected area. Less commonly it results in TIA, stroke, myocardial infarction (MI), and visual symptoms [14]-[16].

The treatment of GCA and TAK and the prevention of ischemic complications have mainly relied on immunosuppression in the form of corticosteroids. Additional immunosuppression is usually required for TAK [17] [18]. As an adjunct therapy, antiplatelet agents have garnered much interest in the prevention and treatment of ischemic complications.

Low dose aspirin (ASA) has been well studied in the prevention and treatment of cardiovascular events decreasing morbidity and mortality in patients with cardiovascular risk factors [19]. Nonetheless, ASA is not without risk. Its inhibitory effects on prostaglandin synthesis can result in gastrointestinal bleeding events, and less commonly, it has been associated with intracranial bleeding. The Antithrombotic Trialists' Collaboration [19] has suggested that its use for primary prevention in cardiovascular disease be assessed on an individual basis. The difficulty with LVV is that we are unable to predict who will develop this condition. Thus the important unanswered question is twofold: 1) is ASA beneficial in preventing ischemic events in LVV and 2) are the benefits present if therapy is started at the time of LVV diagnosis.

There are no randomized controlled trials of antiplatelet or anticoagulant therapies in LVV. Observational studies in GCA patients have found conflicting results regarding ASA in preventing ischemic events. However, in 2008 The European League against Rheumatism (EULAR) [20] recommended that all patients with GCA be on low dose aspirin (ASA). Our study sought to review the literature and evaluate the current evidence for the use of antiplatelet and/or anticoagulant therapies in the prevention of LVV-related ischemic events.

\section{Methods}

\subsection{Literature Search}

We performed a literature search of the following bibliographic databases: Medline (1946 to August 2012), Embase (1974 to August 2012), and Cochrane database. We also performed a search of abstracts available through the American College of Rheumatology (ACR) (2006-2011) and European League against Rheumatism (2002-2012) annual meetings. Our search strategy combined the terms: Giant Cell Arteritis, Temporal Arteritis, Takayasu's Arteritis, aortic arch syndromes, aspirin, acetylsalicylic acid, anticoagulant agent, and ischemia (for full search strategy see Supplementary Table 1).

\subsection{Study Selection}

Studies were included with 1) patients meeting ACR criteria for GCA or TAK and 2) patients treated with AP/AC therapy. Citations were first screened by reviewing the title and abstract to retrieve relevant articles. The retrieved articles were reviewed in full. Case reports, case series, reviews and non-English articles were excluded. A hand search of the references in relevant papers was also conducted to identify any additional articles that would address our objective.

\subsection{Data Extraction and Quality Appraisal}

From the included articles we extracted information including publication type, number of participants, patient characteristics, intervention medications and doses, mean duration of follow-up, number and risk of ischemic 
events, adverse events and whether the study adjusted for confounders. Authors were contacted to obtain missing data.

The quality of data was assessed for the intervention and outcome of interest using two different scales. Cohort studies were appraised using the New Castle Ottawa Scale (NOS) [21]. Cross sectional studies were appraised using the STROBE guidelines [22]. Publication bias was assessed using Funnel plots. Literature search and article review was conducted by two independent assessors and any discrepancies were discussed and agreed upon. Studies were classified as being low, medium or high quality.

\subsection{Statistical Analyses}

Random effects meta-analysis (DerSimonian and Laird method) was performed to determine the primary outcome: risk of severe ischemic events in patients treated with AP/AC versus those not treated with AP/AC expressed as an odds ratio (OR). The majority of the studies reported the outcome of interest as an odds ratio (5/7 studies). For the other 2 studies, we derived the odds ratio from a $2 \times 2$ table. Severe ischemic events were defined as: transient ischemic attack (TIA), stroke, ischemic ocular manifestations and limb claudication. Studies reporting on any ischemic event included jaw claudication in addition to the above manifestations. In studies including multiple treatment groups $(\mathrm{N}=2)$, the mean event rate of the treatment groups was used in the meta-analysis. A priori sensitivity analyses of primary outcome included: exclusion of studies investigating Takayasu's Arteritis and exclusion of studies not performing multivariable analyses to account for confounders. The following subgroup analyses were also performed (established a priori): AP versus AC interventions and studies reporting ischemic events at baseline versus those reporting events at follow-up.

Heterogeneity of the included studies was reported as a Q statistic with associated $I^{2}$ statistic. Meta-regression was performed using method of moments including the following variables that were decided a priori: age, sex, percentage of participants with cardiovascular risk factors, platelet count, and ESR. A p-value $<0.05$ was considered statistically significant. All statistical analyses were performed using comprehensive Meta-analysis version 2 software.

\section{Results}

\subsection{Review of the Literature and Included Studies}

Search results and reasons for exclusion are summarized in Figure 1. A total of 7 studies were included: 6 examining GCA and 1 examining TAK. Of the GCA studies, 5 examined the outcome of severe ischemic events

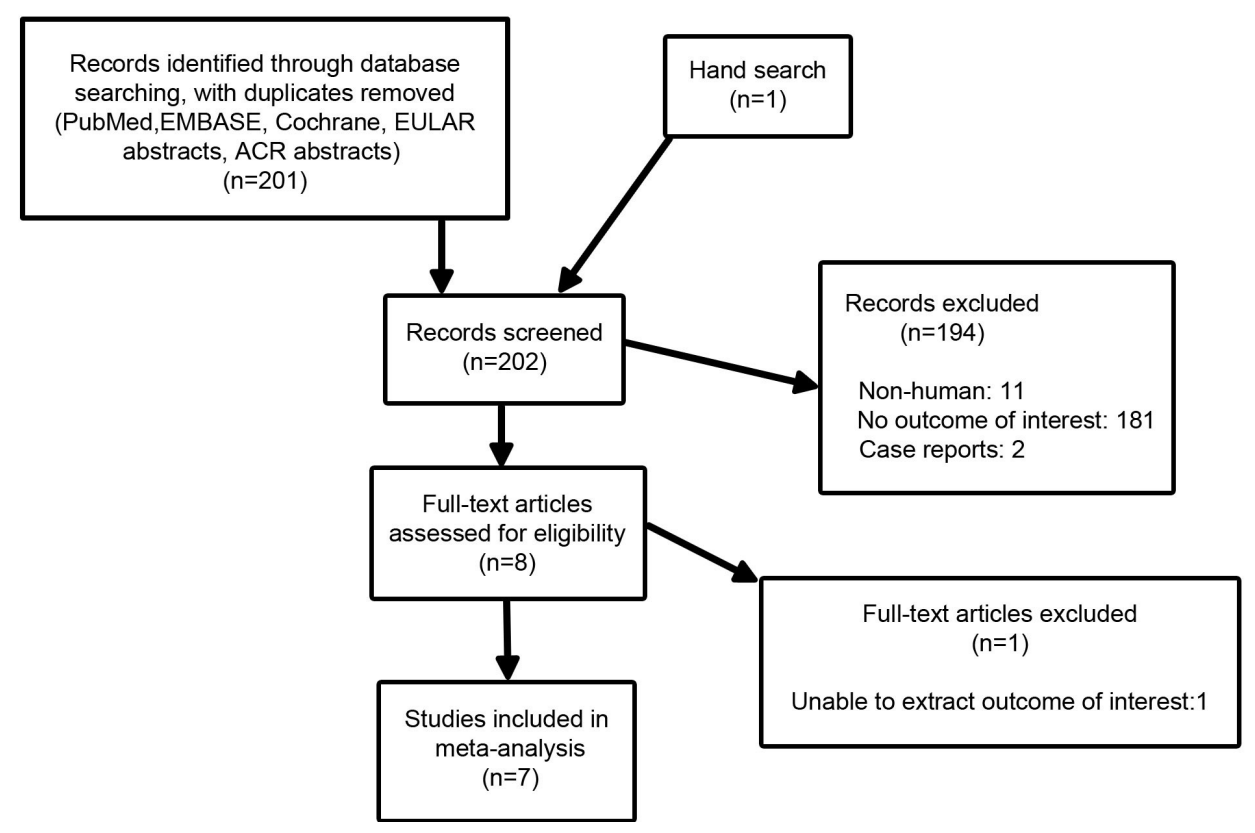

Figure 1. Search results. 
and 3 included data on any ischemic event. The lone TAK study examined severe ischemic events. There was no significant publication bias identified (Supplementary Figure 1). Characteristics of the studies are presented in Table 1: 4 studies were retrospective cohort studies and 3 were cross sectional studies [23]-[29]. Sample sizes ranged from 48 to 210. Mean ages of study participants was 29 for TAK and 73 - 75 for GCA. Overall, 68.0\% of study participants were female and $49.8 \%$ had at least one cardiovascular risk factor. There were a total of 250 patients who received AP/AC therapy and 709 control subjects who did not. 80.8\% of patients treated with AP/AC therapy were on ASA. Of those patients on ASA, doses ranged from $81 \mathrm{mg}-500 \mathrm{mg}$ and $>60 \%$ were taking $325 \mathrm{mg}$ or less. Other AP/AC therapies included 1 patient on ASA in combination with clopidogrel, 4 patients on clopidogrel alone, 7 patients on ticlopidine, 3 patients on triflusal, and 19 patients on a vitamin $\mathrm{K}$ antagonist. Three studies investigating AP use on ischemic events included a total of 16 subjects treated with a vitamin $\mathrm{K}$ antagonist in the control group. Mean duration of follow up in the retrospective cohort studies was 26.4 76.5 months.

Assessment of quality for the intervention and outcome of interest revealed 3 studies of low quality [24] [25] [29] and 4 studies of moderate to high quality [23] [26]-[28] for the outcome of interest via the NOS and STROBE guidelines. The low quality studies were cross-sectional analyses. They lacked information with regards to patients' prior history of cardiovascular and/or cerebrovascular events, there was little discussion as to how ischemic events were assessed, they did not address potential sources of bias or control for potential confounders, and in one study not all patients were accounted for in the analysis. The 4 studies of moderate to high quality were retrospective cohort studies with all patients accounted for in the analysis and 3 of the 4 studies controlling for potential confounders.

\subsection{Efficacy of AP/AC in Preventing Ischemic Events in Patients with Large Vessel Vasculitis}

When all studies were combined, the OR of a severe ischemic event $(\mathrm{N}=7)$ was not significantly different in $\mathrm{AP} / \mathrm{AC}$ treated patients compared to controls, OR $=0.570,95 \% \mathrm{CI} 0.243,1.340$ (Q-value $=33.00, \mathrm{p}<0.0001, I^{2}$ $=81 \%$ ) (Figure 2). Examining any ischemic event $(\mathrm{N}=7)$, there was no significant difference between AP/AC treated patients and controls, OR $=0.594,95 \%$ CI 0.248, 1.421; (Q-value $\left.=33.02, \mathrm{p}<0.0001, I^{2}=82 \%\right)$ (Figure 3). Six of these studies were of GCA patients, one of TAK patients. The OR derived from the TAK study was 0.315 (95\% CI 0.092, 1.079). Removing the TAK study from the meta-analysis did not change the results, OR $=0.66\left(95 \%\right.$ CI 0.24, 1.66) (Q-value 32.47, $\left.\mathrm{p}<0.0001, I^{2}=84 \%\right)$.

Table 1. Included studies and patient characteristics.

\begin{tabular}{|c|c|c|c|c|c|c|}
\hline Study & Study Type & Sample Size, n & $\begin{array}{c}\text { Mean Age, } \\
\text { years }\end{array}$ & $\begin{array}{l}\text { Cardiovascular } \\
\text { Risk Factors (\%) }\end{array}$ & Intervention & $\begin{array}{c}\text { Mean Follow up } \\
\text { (months) }\end{array}$ \\
\hline De Souza et al. ${ }^{23}$ & Retrospective Cohort & 48 & 29 & 92 & $\begin{array}{c}\text { ASA: } 28 \\
\text { ASA + clopidogrel: } 1 \\
\text { Ticlopidine: } 1 \\
\text { AC: } 6\end{array}$ & 76.5 \\
\hline Berger et al. ${ }^{24}$ & Cross-sectional & 85 & 73 & 79 & $\begin{array}{c}\text { ASA: } 22 \\
\text { AC: } 7\end{array}$ & $\mathrm{n} / \mathrm{a}$ \\
\hline Salvarani et al. ${ }^{25}$ & Cross-sectional & 180 & 74 & $65^{*}$ & $\begin{array}{c}\text { ASA: } 21 \\
\text { Ticlopidine: } 3 \\
\text { AC: } 2\end{array}$ & $\mathrm{n} / \mathrm{a}$ \\
\hline $\begin{array}{l}\text { Narvaez } \\
\text { et al. }^{26}\end{array}$ & Retrospective Cohort & 121 & 74 & 34 & $\begin{array}{c}\text { ASA: } 30 \\
\text { Ticlopidine: } 3 \\
\text { Clopidogrel: } 4 \\
\text { AC: } n / a\end{array}$ & 43.2 \\
\hline Lee et al. ${ }^{27}$ & Retrospective Cohort & 143 & 74 & 69 & ASA/clopidogrel/AC: 86 & 50.1 \\
\hline Nesher et al. ${ }^{28}$ & Retrospective Cohort & 175 & 74 & 24 & $\begin{array}{c}\text { ASA: } 36 \\
\text { AC: } 3\end{array}$ & 26.4 \\
\hline $\begin{array}{c}\text { Gonzalez-Gay } \\
\text { et al. }^{29}\end{array}$ & Cross sectional & 210 & 75 & $33^{*}$ & $\begin{array}{c}\text { ASA: } 11 \\
\text { Triflusal: } 3 \\
\text { AC: } 1\end{array}$ & $\mathrm{n} / \mathrm{a}$ \\
\hline
\end{tabular}

*represents\% of patients with hypertension only. ASA: acetylsalisyclic acid; AC: anticoagulation; n/a: not available, n: number. 


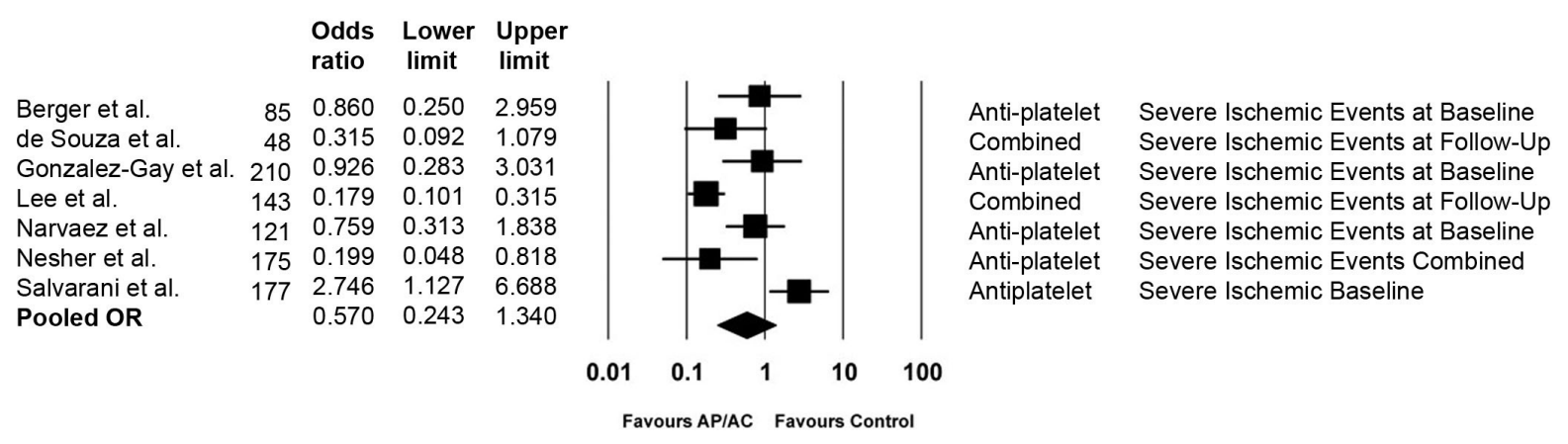

Figure 2. Efficacy of antiplatelet and/or anticoagulant (AP/AC) therapy on severe ischemic events among all included studies.

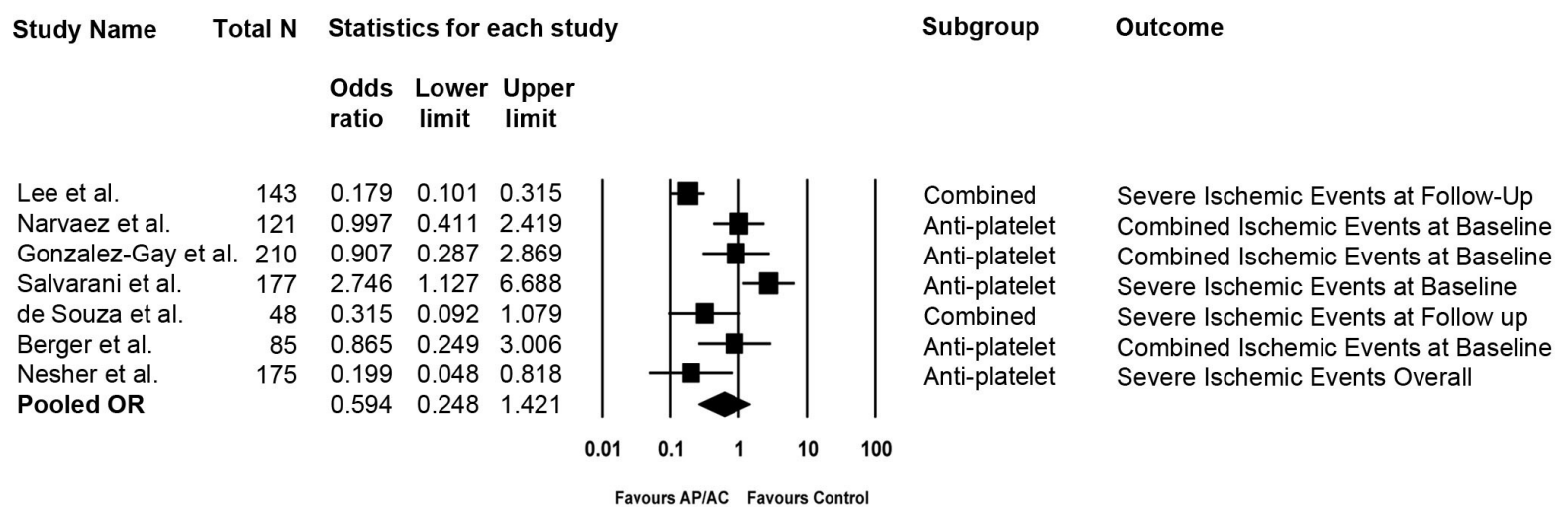

Figure 3. Efficacy of antiplatelet and/or anticoagulant (AP/AC) therapy on any ischemic event among all included studies.

The above analyses included studies that did not account for cardiovascular risk factors, such as hypertension, dyslipidemia, smoking history, diabetes, and family history of cardiovascular disease, which are potential confounders. Three GCA studies reported results of multivariable logistic regression accounting for significant cardiovascular risk factor variables [26]-[28]. Meta-analysis of these three studies revealed that AP/AC was associated with a significant protective effect for severe ischemic events: OR = 0.298, 95\% CI 0.106, 0.839 (Q-value $=10.53, \mathrm{p}=0.005, I^{2}=73 \%$ (Figure 4). The TAK study [23] accounted for cardiovascular risk factors using a Cox proportional-hazards regression model and therefore could not be pooled with the other studies. However, it also showed a benefit to AP/AC therapy with a HR of $0.055,95 \%$ CI $0.006,0.514 ; p=0.011$. Authors of the other studies were contacted and data on confounders was obtained from Gonzalez-Gay et al. [29]. We used this data to perform multivariable logistic regression with the following variables: age, sex, hypertension, hyperlipidemia, diabetes and smoking. Risk of ischemic events was not significantly associated with AP/AC (OR 1.596, $95 \%$ CI $0.813,3.135$ ) and when including these results in the meta-analysis the protective effect of AP/AC was no longer significant (OR $0.475,95 \%$ CI $0.148,1.520)\left(\mathrm{Q}\right.$-value $=27.60, \mathrm{p}<0.0001, I^{2}=88 \%$ ).

\subsection{Subgroup Analyses and Meta-Regression}

A subgroup analysis comparing either AP ( $\mathrm{N}=7$ ) [23]-[29] or AC $(\mathrm{N}=2)$ [23] [27] therapy alone versus control in reducing ischemic events in LVV revealed no significant difference between groups (AP: OR 0.41, 95\% CI 0.17, 1.01; AC: 0.67, 95\% CI 0.04, 10.49); $\mathrm{p}=0.756$ (Table 2). Comparing the OR of ischemic events between AP/AC and control within 1 month of LVV diagnosis (baseline) and follow-up (26 - 76 months) was also performed (Table 2). At baseline, there was no significant difference in the OR of ischemic events among AP/AC and control groups $(\mathrm{N}=5)(2, \mathrm{OR}=0.87,95 \% \mathrm{CI} 0.40,1.92$. Three studies provided follow-up data [24]-[26] [28] [29] and meta-analysis showed benefit for AP/AC: OR = 0.18, 95\% CI 0.04, 0.83 .

The majority of patients initiated AP/AC prior to LVV diagnosis; however, three studies included patients 
Study name $\underline{\text { Total } \mathrm{N}}$

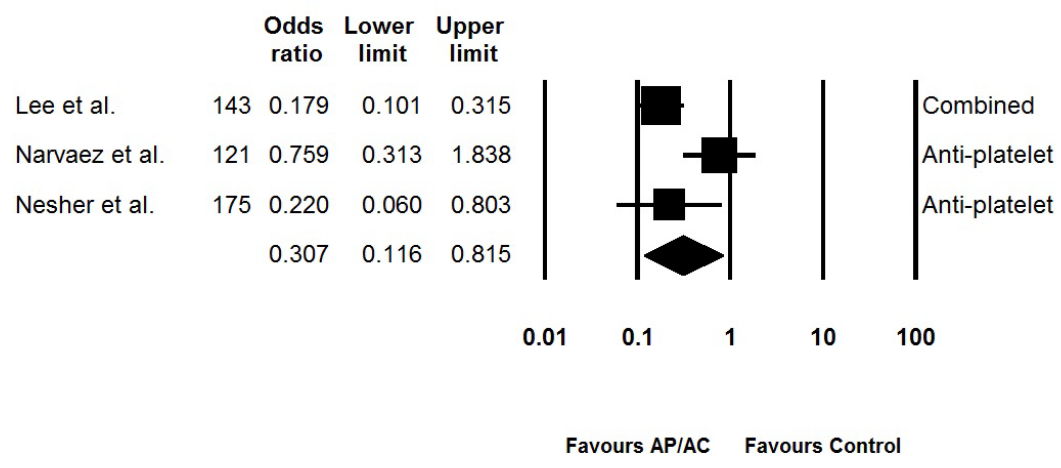

\section{Subgroup within study Outcome}

Severe Ischemic Follow-up

Severe Ischemic Baseline

Severe Ischemic Baseline

Figure 4. Efficacy of AP/AC therapy on severe ischemic events when controlling for cardiovascular risk factors.

Table 2. Subgroup analyses comparing AP versus AC efficacy and AP/AC therapy at baseline versus follow-up.

\begin{tabular}{cccccc}
\hline Time of Analysis & N studies & OR (95\% CI) & Q statistic & P value & $\boldsymbol{I}^{2}$ statistic \\
\hline AP & 7 & $0.41(0.17,1.01)$ & 39.04 & $<0.0001$ & $82 \%$ \\
AC & 2 & $0.67(0.04,10.49)$ & 5.65 & 0.017 & $82 \%$ \\
Baseline & 5 & $0.87(0.40,1.92)$ & 10.63 & 0.031 & $63 \%$ \\
Follow-up & 4 & $0.18(0.04,0.83)$ & 12.81 & 0.012 & $69 \%$ \\
\hline
\end{tabular}

AP: antiplatelet; AC: anticoagulation; N: number, OR: odds ratio.

who started AP/AC subsequent to the diagnosis of LVV: 1 TAK study and 2 GCA studies. In the TAK study [23], all patients had AP/AC started after diagnosis. Of the GCA studies, Nesher et al. [28] had 41/73 and Gonzalez-Gay et al. [29] had 29/79 patients treated with AP/AC start therapy after GCA diagnosis. These studies did not separately report risk of ischemic events in patients first started on AP/AC after diagnosis of LVV compared to those never treated with AP/AC. However, data from the authors was obtained from Gonzalez-Gay et al. [29] and the risk of severe ischemic events in patients started on AP/AC after GCA diagnosis compared to controls was: OR 1.414, 95\% CI 0.544, 3.672.

Meta-regression was also performed to investigate sources of heterogeneity. The mean difference in ORs for any ischemic event was significantly affected by increasing age, excluding the TAK study (Supplementary Figure 2). Mean differences in ORs for any ischemic event were not significantly affected by percentage of participants with cardiovascular risk factors, platelet count, or baseline ESR, but analyses were limited by small sample size.

\section{Discussion}

This is the first meta-analysis to examine the efficacy of antiplatelet and/or anticoagulant therapy (AP/AC) in preventing ischemic events in Large Vessel Vasculitis. This study suggests that AP therapy has a significant protective effect against severe ischemic events in LVV at follow-up. However, at baseline, studies had discrepant results and the benefit of AP/AC at preventing ischemic events was not significant. One study investigated TAK and this study showed a significant benefit for AP/AC.

The mechanism by which AP could be protective against ischemic events in patients with LVV has not been studied. Low dose ASA has been observed to inhibit thrombosis in cardiovascular disease by inhibiting platelet activation and aggregation as well as improving endothelial dysfunction [30]. This protective mechanism may explain ASA's benefits in TAK as thromboxane B2 levels have been observed to increase in the affected limb of TAK patients and decrease in response to ASA treatment [31]-[33]. In GCA, the pathogenesis leading to occlusive events appears to be different. The activation of $\mathrm{T}$ lymphocytes, macrophages, and proinflammatory cytokines has been implicated with subsequent intimal proliferation leading to blood vessel occlusion and ischemic events [34]-[36]. Even low dose ASA has been shown to possess anti-inflammatory effects and could certainly be working through this mechanism [37] [38]. In animal studies in which inflamed temporal arteries were grafted to mice, Weyand et al. (2002) [39] showed that ASA inhibits interferon gamma production, a cytokine that is elevated in inflammatory lesions of GCA. 
Due to the low prevalence of LVV and rare incidence of ischemic events, even with broad inclusion criteria, only 7 studies were included in this meta-analysis, all of which were observational in design. Therefore, we lacked power for some of the subgroup analyses. Furthermore, 3 of the 7 studies in this meta-analysis were of poor methodological quality: information with regards to patients' history of cardiovascular and/or cerebrovascular events was missing, a discussion as to how ischemic events were assessed was insufficient, and there was a lack of acknowledgement to potential sources of bias or control for potential confounders. Previous studies have demonstrated an important role of cardiovascular risk factors in the development of ischemic events in GCA [25] [29]. For example, the presence of hypertension in GCA has been observed to increase one's risk of a severe ischemic event [25]. Furthermore, epidemiologic studies have found that cardiovascular disease itself is accelerated in LVV [40]. Controlling for these confounding factors may help to explain some of the discrepancies in the literature examining the efficacy of AP therapy in preventing LVV-associated ischemic events. A priori, we felt it was important to conduct sensitivity analyses removing studies that did not account for confounders; however, this did not significantly change the results.

A priori sensitivity analyses and meta-regressions were performed to help explain heterogeneity. Heterogeneity remained high when analyses were limited to studies with follow-up data or to those that accounted for cardiovascular risk factors. Our meta-regression analyses found that the results were significantly affected by increasing age in GCA. There are several other reasons that may explain the heterogeneity observed among studies: differences in follow-up, types and doses of AP/AC and immunosuppression, disease and treatment duration, disease severity at presentation and population differences (genetics and exposures). In addition, the definition and determination of outcomes varied amongst studies; for example, ischemic events were frequently reported based on symptomatology and only 3 of 7 studies explicitly mentioned the use of diagnostic imaging to objectively assess cerebral ischemic event.

The question of when AP/AC should be started remains unclear. In the TAK study all except one patient were started on AP/AC after diagnosis and AP was shown to significantly reduce ischemic events with a HR of 0.06 [23]. For the GCA studies, 72.8\% of patients were initiated on AP/AC prior to the diagnosis of vasculitis, most often because of pre-existing cardiovascular risk factors. As there is no means available to predict development of LVV, primary prevention is not feasible. None of the GCA studies reported the effect of starting AP/AC after LVV diagnosis. However, there was a large reduction in ischemic events, OR 0.18 in LVV patients at 2 - 7 years follow-up. Post hoc analyses of data for Gonzalez-Gay et al., which included only patients initiated on AP/AC after diagnosis, failed to show a benefit for AP/AC at decreasing ischemic events.

With respect to adverse events of AP/AC, only 3 studies in this meta-analysis reported bleeding events associated with AP use. There were 4 events in total; these included an intracranial bleed, two gastrointestinal bleeds and another event being attributed to a uterine myoma [23] [27] [28]. More research is needed to examine whether the use of AP/AC in patients with LVV confers a greater risk of bleeding than patients without LVV. In addition, no conclusions can be made regarding AC therapy alone as the majority of patients were treated with AP (80.8\% of patients on AP/AC therapy were on ASA). Three of the studies investigating the benefit of AP therapy included a total of 16 control subjects on a vitamin $\mathrm{K}$ antagonist, which may have underestimated protective effect of AP in LVV.

In this meta-analysis, we demonstrate a large magnitude of effect of AP/AC therapy at follow-up for preventing severe ischemic events. However, these results must be interpreted with caution: there is only 1 TAK study and 3 GCA studies with follow-up data. In addition, the majority of patients in these studies were started on AP/AC prior to diagnosis of LVV. Future cohorts of LVV patients should report the risk of ischemic events in subjects initiated on AP/AC at the time of diagnosis.

\section{Acknowledgements}

Michael S. Lee and Alexandre W. S. de Souza for their helpful responses to queries.

\section{Conflicts of Interests}

Authors have no conflicts of interest to declare. This study was not funded.

\section{References}

[1] Gonzalez-Gay, M.A., Vazquez-Rodriguez, T.R., Lopez-Diaz, M.J., Miranda-Filloy, J.A., Gonzalez-Juanatey, C., Mar- 
tin, J., et al. (2009) Epidemiology of Giant Cell Arteritis and Polymyalgia Rheumatica. Arthritis \& Rheumatology, 61, 1454-1461. http://dx.doi.org/10.1002/art.24459

[2] Johnston, S.L., Lock, R.J. and Gompels, M.M. (2002) Takayasu Arteritis: A Review. Journal of Clinical Pathology, 55, 481-486. http://dx.doi.org/10.1136/jcp.55.7.481

[3] Hunder, G.G. (2002) Epidemiology of Giant-Cell Arteritis. Cleveland Clinic Journal of Medicine, 69, SII79-SII82. http://dx.doi.org/10.3949/ccjm.69.Suppl 2.SII79

[4] Weyand, C.M. and Goronzy, J.J. (2003) Medium- and Large-Vessel Vasculitis. The New England Journal of Medicine, 349, 160-169. http://dx.doi.org/10.1056/NEJMra022694

[5] Salvarani, C., Cantini, F., Boiardi, L. and Hunder, G.G. (2002) Polymyalgia Rheumatica and Giant-Cell Arteritis. The New England Journal of Medicine, 347, 261-271. http://dx.doi.org/10.1056/NEJMra011913

[6] Hayreh, S.S., Podhajsky, P.A. and Zimmerman, B. (1998) Ocular Manifestations of Giant Cell Arteritis. American Journal of Ophthalmology, 125, 509-520. http://dx.doi.org/10.1016/S0002-9394(99)80192-5

[7] Caselli, R.J., Hunder, G.G. and Whisnant, J.P. (1988) Neurologic Disease in Biopsy-Proven Giant Cell (Temporal) Arteritis. Neurology, 38, 352-359. http://dx.doi.org/10.1212/WNL.38.3.352

[8] Font, C., Cid, M.C., Coll-Vinent, B., Lopez-Soto, A. and Grau, J.M. (1997) Clinical Features in Patients with Permanent Visual Loss Due to Biopsy-Proven Giant Cell Arteritis. British Journal of Rheumatology, 36, 251-254. http://dx.doi.org/10.1093/rheumatology/36.2.251

[9] Gonzalez-Gay, M.A., Alonso, M.D., Aguero, J.J., Bal, M., Fernandez-Camblor, B. and Sanchez-Andrade, A. (1992) Temporal Arteritis in a Northwestern Area of Spain: Study of 57 Biopsy Proven Patients. British Journal of Rheumatology, 19, 277-280.

[10] Gonzalez-Gay, M.A., Blanco, R., Rodriguez-Valverde, V., Martinez-Taboada, V.M., Delgado-Rodriguez, M., Figueroa, M., et al. (1998) Permanent Visual Loss and Cerebrovascular Accidents in Giant Cell Arteritis: Predictors and Response to Treatment. Arthritis \& Rheumatology, 41, 1497-1504. http://dx.doi.org/10.1002/1529-0131(199808)41:8<1497::AID-ART22>3.0.CO;2-Z

[11] Perruquet, J.L., Davis, D.E. and Harrington, T.M. (1986) Aortic Arch Arteritis in the Elderly. An Important Manifestation of Giant Cell Arteritis. Archives of Internal Medicine, 146, 289-291. http://dx.doi.org/10.1001/archinte.1986.00360140107015

[12] Ninet, J.P., Bachet, P., Dumontet, C.M., Du Colombier, P.B., Stewart, M.D. and Pasquier, J.H. (1990) Subclavian and Axillary Involvement in Temporal Arteritis and Polymyalgia Rheumatica. American Journal of Medicine, 88, 13-20. http://dx.doi.org/10.1016/0002-9343(90)90121-S

[13] Klein, R.G., Hunder, G.G., Stanson, A.W. and Sheps, S.G. (1975) Large Artery Involvement in Giant Cell (Temporal) Arteritis. Annals of Internal Medicine, 83, 806-812. http://dx.doi.org/10.7326/0003-4819-83-6-806

[14] Mwipatayi, B.P., Jeffery, P.C., Beningfield, S.J., Matley, P.J., Naidoo, N.G., Kalla, A.A., et al. (2005) Takayasu Arteritis: Clinical Features and Management: Report of 272 Cases. ANZ Journal of Surgery, 75, 110-117. http://dx.doi.org/10.1111/j.1445-2197.2005.03312.X

[15] Kerr, G.S., Hallahan, C.W., Giordano, J., Leavitt, R.Y., Fauci, A.S., Rottem, M., et al. (1994) Takayasu Arteritis. Annals of Internal Medicine, 120, 919-929. http://dx.doi.org/10.7326/0003-4819-120-11-199406010-00004

[16] Park, M.C., Lee, S.W., Park, Y.B., Chung, N.S. and Lee, S.K. (2005) Clinical Characteristics and Outcomes of Takayasu's Arteritis: Analysis of 108 Patients Using Standardized Criteria for Diagnosis, Activity Assessment, and Angiographic Classification. Scandinavian Journal of Rheumatology, 34, 284-292. http://dx.doi.org/10.1080/03009740510026526

[17] Isobe, M. (2013) Takayasu Arteritis Revisited: Current Diagnosis and Treatment. International Journal of Cardiology, 168, 3-10. http://dx.doi.org/10.1016/j.ijcard.2013.01.022

[18] Borg, F.A. and Dasgupta, B. (2009) Treatment and Outcomes of Large Vessel Arteritis. Best Practice and Research Clinical Rheumatology, 23, 325-337.

[19] Antithrombotic Trialists’ (ATT) Collaboration, Baigent, C., Blackwell, L., Collins, R., Emberson, J., Godwin, J., et al. (2009) Aspirin in the Primary and Secondary Prevention of Vascular Disease: Collaborative Meta-Analysis of Individual Participant Data from Randomised Trials. Lancet, 373, 1849-1860. http://dx.doi.org/10.1016/S0140-6736(09)60503-1

[20] Mukhtyar, C., Guillevin, L., Cid, M.C., Dasgupta, B., de Groot, K., Gross, W., et al. (2009) EULAR Recommendations for the Management of Large Vessel Vasculitis. Annals of the Rheumatic Diseases, 68, 318-323. http://dx.doi.org/10.1136/ard.2008.088351

[21] The Newcastle-Ottawa Scale (NOS) for Assessing the Quality if Nonrandomized Studies in Meta-Analyses. 2011. http://www.ohri.ca/programs/clinical epidemiology/oxford.htm 
[22] Vandenbroucke, J.P., von Elm, E., Altman, D.G., Gotzsche, P.C., Mulrow, C.D., Pocock, S.J., et al. (2007) Strengthening the Reporting of Observational Studies in Epidemiology (STROBE): Explanation and Elaboration. Annals of Internal Medicine, 147, W163-W194. http://dx.doi.org/10.7326/0003-4819-147-8-200710160-00010-w1

[23] de Souza, A.W., Machado, N.P., Pereira, V.M., Arraes, A.E., Reis Neto, E.T., Mariz, H.A. and Sato, E.I. (2010) Antiplatelet Therapy for the Prevention of Arterial Ischemic Events in Takayasu Arteritis. Circulation Journal: Official Journal of the Japanese Circulation Society, 74, 1236-1241.

[24] Berger, C.T., Wolbers, M., Meyer, P., Daikeler, T. and Hess, C. (2009) High Incidence of Severe Ischaemic Complications in Patients with Giant Cell Arteritis Irrespective of Platelet Count and Size, and Platelet Inhibition. Rheumatology (Oxford), 48, 258-261. http://dx.doi.org/10.1093/rheumatology/ken480

[25] Salvarani, C., Della Bella, C., Cimino, L., Macchioni, P., Formisano, D., Bajocchi, G., Pipitone, N., Catanoso, M.G., Restuccia, G., Ghinoi, A. and Boiardi, L. (2009) Risk Factors for Severe Cranial Ischaemic Events in an Italian Population-Based Cohort of Patients with Giant Cell Arteritis. Rheumatology, 48, 250-253.

[26] Narváez, J., Bernad, B., Gómez-Vaquero, C., García-Gómez, C., Roig-Vilaseca, D., Juanola, X., Rodriguez-Moreno, J., Nolla, J.M. and Valverde, J. (2008) Impact of Antiplatelet Therapy in the Development of Severe Ischemic Complications and in the Outcome of Patients with Giant Cell Arteritis. Clinical and Experimental Rheumatology, 26, S57-S62.

[27] Lee, M.S., Smith, S.D., Galor, A. and Hoffman, G.S. (2006) Antiplatelet and Anticoagulant Therapy in Patients with Giant Cell Arteritis. Arthritis and Rheumatism, 54, 3306-3309.

[28] Nesher, G., Berkun, Y., Mates, M., Baras, M., Rubinow, A. and Sonnenblick, M. (2004) Low-Dose Aspirin and Prevention of Cranial Ischemic Complications in Giant Cell Arteritis. Arthritis and Rheumatism, 50, 1332-1337.

[29] Gonzalez-Gay, M.A., Pineiro, A., Gomez-Gigirey, A., Garcia-Porrua, C., Pego-Reigosa, R., Dierssen-Sotos, T. and Llorca, J. (2004) Influence of Traditional Risk Factors of Atherosclerosis in the Development of Severe Ischemic Complications in Giant Cell Arteritis. Medicine (Baltimore), 83, 342-347. http://dx.doi.org/10.1097/01.md.0000145369.25558.b5

[30] Dai, Y. and Ge, J. (2012) Clinical Use of Aspirin in Treatment and Prevention of Cardiovascular Disease. Thrombosis, 2012, Article ID: 245037.

[31] Numano, F., Shimokado, K., Kishi, Y., Nishiyama, K., Turkoglu, C., Yajima, M., Numano, F. and Maezawa, H. (1982) Changes in the Plasma Levels of Thromboxane $\mathrm{B}_{2}$ and Cyclic Nucleotides in Patients with Takayasu Disease. Japanese Circulation Journal, 46, 16-20. http://dx.doi.org/10.1253/jcj.46.16

[32] Numano, F., Maruyama, Y., Koyama, T. and Numano, F. (1986) Antiaggregative Aspirin Dosage at the Affected Vessel Wall. Angiology, 37, 695-701. http://dx.doi.org/10.1177/000331978603701001

[33] Kasuya, N., Kishi, Y., Isobe, M., Yoshida, M. and Numano, F. (2006) P-Selectin Expression, but Not GPIIb/IIIa Activation, Is Enhanced in the Inflammatory Stage of Takayasu's Arteritis. Circulation Journal, 70, 600-604. http://dx.doi.org/10.1253/circj.70.600

[34] Borchers, A.T. and Gershwin, M.E. (2012) Giant Cell Arteritis: A Review of Classification, Pathophysiology, Geoepidemiology and Treatment. Autoimmunity Reviews, 11, A544-A554.

[35] Ly, K.H., Regent, A., Tamby, M.C. and Mouthon, L. (2010) Pathogenesis of Giant Cell Arteritis: More than Just an Inflammatory Condition? Autoimmunity Reviews, 9, 635-645. http://dx.doi.org/10.1016/j.autrev.2010.05.002

[36] Weyand, C.M. and Goronzy, J.J. (2003) Giant-Cell Arteritis and Polymyalgia Rheumatica. Annals of Internal Medicine, 139, 505-515.

[37] Chiang, N., Bermudez, E.A., Ridker, P.M., Hurwitz, S. and Serhan, C.N. (2004) Aspirin Triggers Antiinflammatory 15-epi-lipoxin $\mathrm{A}_{4}$ and Inhibits Thromboxane in a Randomized Human Trial. Proceedings of the National Academy of Sciences of the United States of America, 101, 15178-15183. http://dx.doi.org/10.1073/pnas.0405445101

[38] Santilli, F., Davi, G., Consoli, A., Cipollone, F., Mezzetti, A., Falco, A., Taraborelli, T., Devangelio, E., Ciabattoni, G., Basili, S. and Patrono, C. (2006) Thromboxane-Dependent CD40 ligand Release in Type 2 Diabetes Mellitus. Journal of the American College of Cardiology, 47, 391-397. http://dx.doi.org/10.1016/j.jacc.2005.03.079

[39] Weyand, C.M., Kaiser, M., Yang, H., Younge, B. and Goronzy, J.J. (2002) Therapeutic Effects of Acetylsalicylic Acid in Giant Cell Arteritis. Arthritis \& Rheumatism, 46, 457-466. http://dx.doi.org/10.1002/art.10071

[40] Cohen Tervaert, J.W. (2013) Cardiovascular Disease Due to Accelerated Atherosclerosis in Systemic Vasculitides. Best Practice \& Research Clinical Rheumatology, 27, 33-44. http://dx.doi.org/10.1016/j.berh.2012.12.004 


\section{Supplement}

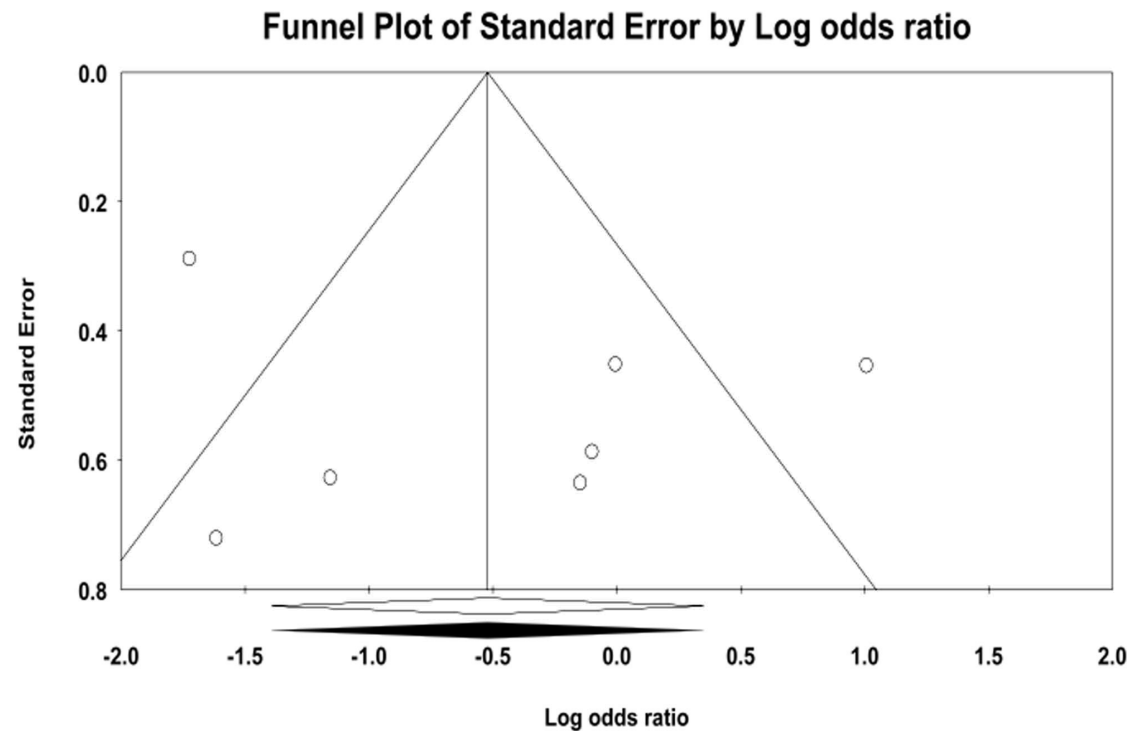

Supplementary Figure 1. Funnel plot for included studies; observed studies (open circles); observed mean difference in ischemic events odds ratio (filled diamond); imputed mean difference in ischemic events odds ratio (filled diamond).

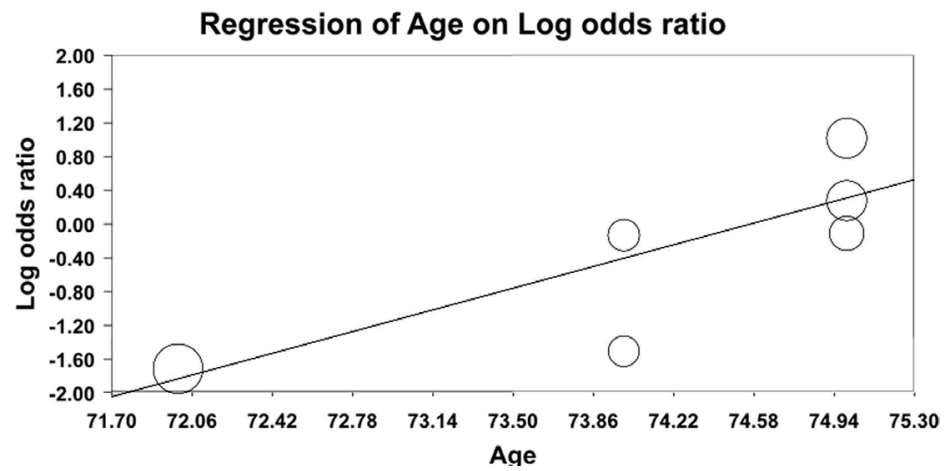

Supplementary Figure 2. Meta-regression for effect of age on difference in mean ischemic event odds ratio (OR) for AP/AC therapy versus controls in patients with GCA.

\section{Supplementary Table 1. Search strategy.}

1. giant cell arteritis.mp. or giant cell arteritis/

2. temporal arteritis.mp. or temporal arteritis/

3. aortic arch syndromes.mp. or aorta arch syndrome/

$$
\text { 4. } 1 \text { or } 2 \text { or } 3
$$

5. aspirin.mp. or acetylsalicylic acid/

6. anticoagulant agent/

7. exp Platelet Aggregation Inhibitors/

$$
8.5 \text { or } 6 \text { or } 7
$$

9. exp ischemia/ or Ischemia.mp.

10. optic neuropathy, ischemic.mp. or Optic Neuropathy, Ischemic/

11. exp Myocardial Ischemia/

12. exp Brain Ischemia/

13. 9 or 10 or 11 or 12

14. 4 and 8 and 13 